\title{
Cervical spinal dermal sinus associated with intramedullary spinal cord abscess
}

Seio dérmico espinhal cervical associado com abscesso intramedular espinhal

Bernardo Carvalho Muniz¹, Bruno Niemeyer de Freitas Ribeiro', Gabriel Mufarrej', Nina Ventura Wilner', Emerson Leandro Gasparetto ${ }^{1}$

A female, aged 21 months, presented with fever and an orifice with output of purulent material, observed in the upper cervical region. Spinal and brain MRI are displayed in Figures A to $\mathrm{D}$. The radiological diagnosis, with subsequent histopathologic confirmation, was dermal sinus associated with intramedullary spinal cord abscess.
The dermal sinus is a congenital anomaly resulting from incomplete division of ectodermal epithelium with neuroectodermal, in early fetal life, and the thoraco-lumbar spine is most frequently affected. An abscess is a known complication, though rare, especially in this location ${ }^{1,2}$.
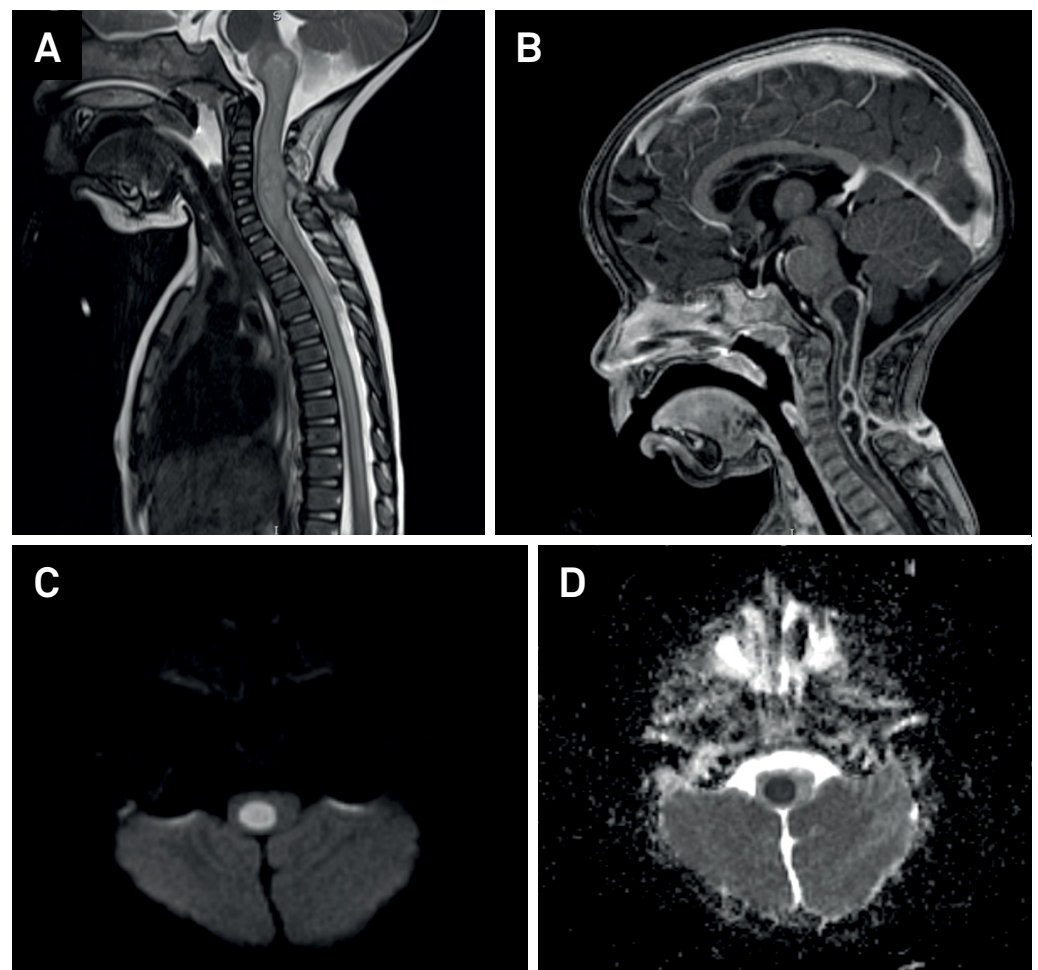

Figure. Intramedullary spinal cord abscess characterized by a heterogeneous T2-hyperintense lesion that expands the cord, extending superiorly to the medula oblongata and inferiorly, approximately to the level of D3 (A). The lesion is predominantly hyperintense on T1, demonstrates thick peripheral enhancement (B) and true restricted diffusion ( $\mathrm{C}$ and $\mathrm{D})$. The dermal sinus is characterized by a fistulous path between the skin and the spinal cord, in this case, the cervical spine at the level of C4, with peripheral enhancement (B).

\section{References}

1. Chidambaram B, Balasubramaniam V. Intramedullary abscess of the spinal cord. Pediatr Neurosurg. 2001;34(1):43-4.

http://doi.org/10.1159/000055991
2. Morimoto K, Takemoto O. Nakamura H, Takeuchi M. Spinal dermal sinus associated with intramedullary abscess and dermoid. Pediatr Neurosurg. 2003;39(4):225-6. http://doi.org/10.1159/000072478 